\title{
ESTUDO DO COMPORTAMENTO MECÂNICO EM TRAÇÃO DO COBRE ELETROLÍTICO C11000 E DO COBRE CROMO C18200 ENSAIADOS EM ALTA TEMPERATURA *
}

\author{
Luan Bezerra Silva ${ }^{1}$ \\ Sheila Medeiros de Carvalho
}

\section{Resumo}

O presente trabalho pretende estudar o comportamento mecânico do cobre eletrolítico C11000 e da liga de cobre cromo C18200. Esses dois materiais são objetos de estudos da equipe técnica que está desenvolvendo a câmara de combustão do motor foguete propelente líquido L75. Atualmente, não há disponível na literatura informações sobre o comportamento mecânico desses materiais em altas temperaturas. A fim de suprir essa necessidade, foram realizados ensaios de tração a quente, no intervalo de temperatura de 27 a $500^{\circ} \mathrm{C}$. Adicionalmente, foram realizados ensaios de dureza Vickers e metalografia para avaliar a capacidade do material em resistir mecanicamente em altas temperaturas. Os resultados obtidos demostraram que o cobre eletrolítico sofre amolecimento a partir de $400^{\circ} \mathrm{C}$ e que o cobre cromo, apesar de apresentar elevada resistência mecânica quando comparado com o cobre eletrolítico C11000, é um material frágil.

Palavras-chave: Cobre eletrolítico C11000; Cobre cromo C18200; Tração a quente; Comportamento mecânico.

\section{STUDY OF THE TENSILE MECHANICAL BEHAVIOR OF ELECTROLYTIC COPPER C11000 AND COPPER-CHROME C18200 AT HIGH TEMPERATURES}

\section{Abstract}

This work intends to study the mechanical behavior of the electrolytic copper C11000 and the copper-chromium alloy $\mathrm{C} 18200$. These materials have been considered by the technical staff for the combustion chamber of the L75 liquid fuel rocket engine. Currently it is verified an absence of literature information about the mechanical behavior at high temperatures. In order to fulfill this need, it was realized hot tensile tests on the range 27 to $500^{\circ} \mathrm{C}$. Furthermore, Vickers hardness and metallography were used to characterize the alloys at high temperatures. The results shown that the electrolytic copper began to be softened at temperarutes exceeding $400^{\circ} \mathrm{C}$. The copper-chromium alloy, although presenting a high mechanical resistance, is brittle at these temperatures.

Keywords: Copper C11000; Copper C18200; Tensile testing; Mechanical properties 


\section{INTRODUÇÃO}

No que tange ao âmbito tecnológico, novos materiais, processos e produtos são continuamente estudados e implantados em diversas aplicações. Isto causa impacto evidente no processo produtivo, na economia e na proteção ao meio ambiente.

No contexto aerospacial e militar, a necessidade de inovação viabilizou o surgimento do projeto do Motor Foguete a Propelente Líquido L75 (MFPL 75), pelo Instituto de Aeronáutica e Espaço [1]. Um dos componentes necessários do MFPL 75 é a sistema de combustão, Figura 1. Dentre os principais componentes apresentados na Figura 1, a câmara de combustão é de particular interesse, no que tange ao projeto e nos processos de fabricação. Na câmara de combustão ocorre a queima do propelente produzindo gases que podem atingir temperaturas da ordem de $3.300{ }^{\circ} \mathrm{C}$.

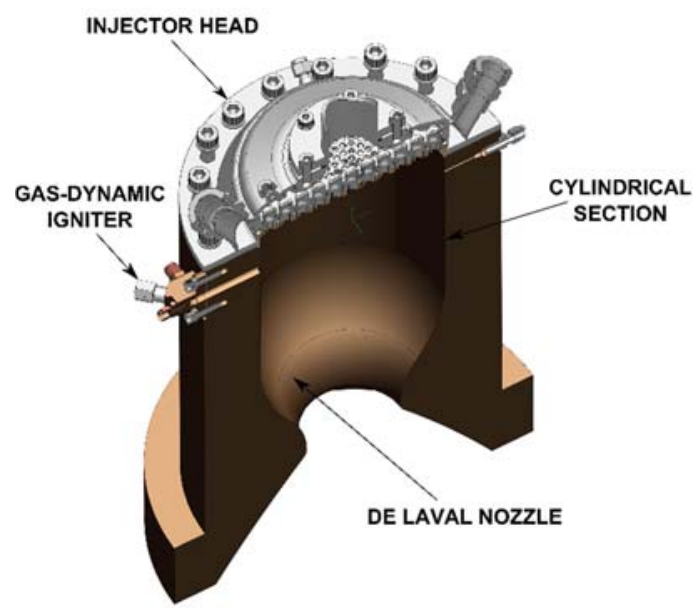

Figura 1. Modelo esquemático do sistema de combustão do MFPL 75.

A seleção de um material adequado para a câmara capacitiva é vital para não comprometer a aplicabilidade do componente. No processo de seleção de materiais para uso na câmara capacitiva deve-se considerar uma relação de propriedades mecânicas, térmicas e custo. Essencialmente, a análise do comportamento mecânico em tração em altas temperaturas, bem como o comportamento físico do material [2] forma a base para a escolha do material. Estudos anteriores abordam o uso do cobre eletrolítico C11000 e a liga cobre cromo C18200, materiais que possuem boa resistência mecânica e alta condutividade térmica.

Carreker e colaboradores [3] obtiveram amostras de cobre $(99,999 \%)$ com tamanho médio de grãos diferentes $(0,012 ; 0,015 ; 0,030 ; 0,045$ e $0,090 \mathrm{~mm}$.), variando as temperaturas de recozimento de $250,350,550,750$ e $950^{\circ} \mathrm{C}$, respectivamente. Os autores observaram que nos ensaios de tração em baixas temperaturas, a tensão máxima é mais dependente do tamanhão de grão.

O efeito da temperatura no limite de resistência à tração da liga cobre cromo (1\% peso) foi estudado também por Ghica e Colaboradores [4]. As amostras foram primeiramente solubilizadas a $1000^{\circ} \mathrm{C}$ por 3 horas e, posteriormente, envelhecidas a $475^{\circ} \mathrm{C}$ por 4 horas. Os autores observaram que a tensão máxima a $300^{\circ} \mathrm{C}$ diminuiu $25 \%$ em relação à tensão máxima à temperatura ambiente, devido ao crescimento dos grãos.

Verifica-se então que o uso do cobre como material para fabricação do motor foguete necessita de estudos detalhados sobre o seu comportamento mecânico em altas temperaturas. Este é o objetivo do presente estudo. 


\section{MATERIAIS E MÉTODOS}

Os materiais utilizados no presente trabalho foram o cobre eletrolítico C11000 e a liga de cobre cromo C18200, adquiridas da empresa ARTISA Metais na forma de barras de 19,05 mm de diâmetro (3/4 polegadas). O cobre eletrolítico possui 99,92\% de pureza (composição nominal). A Tabela 1 apresenta a composição química nominal do Cobre Cromo C18200. A Tabela 2 apresenta os dados de microdureza Vickers do cobre eletrolítico C11000 e do cobre cromo C18200 como recebido.

Tabela 1. Composição química do cobre cromo C18200 (\% peso)

\begin{tabular}{lllllllllll}
\hline $\mathbf{C u}$ & $\mathbf{N i}$ & $\mathbf{P b}$ & $\mathbf{S n}$ & $\mathbf{P}$ & $\mathbf{A l}$ & $\mathbf{F e}$ & $\mathbf{Z n}$ & $\mathbf{Z r}$ & $\mathbf{C r}$ & $\mathbf{S i}$ \\
\hline 99,139 & 0,005 & 0,005 & 0,005 & 0,007 & 0,008 & 0,02 & 0,032 & 0,072 & 0,704 & 0,003 \\
\hline
\end{tabular}

Tabela 2. Valores médios e desvio padrão de microdureza Vickers (carga 50 gf / 9s)

\begin{tabular}{cc}
\hline Material & Microdureza Vickers (HV) \\
\hline C11000 & $119 \pm 2$ \\
C18200 & $180 \pm 7$ \\
\hline
\end{tabular}

A preparação metalográfica das amostras foi realizada no Instituto de Estudos Avançados (IEAv). Essa etapa consistiu em:

- $\quad$ Embutimento da amostra em baquelite na embutidora Arotec modelo PRE-30.

- Desbaste utilizando as lixas na seqüência granulométrica de 100, 200, 400, 600 e $1200 \mu \mathrm{m}$. O equipamento utilizado foi uma politriz AROTEC/APL-4. A rotação utilizada no lixamento foi de 300 RPM.

- Polimento mecânico e manual com panos circulares auto-adesivos Arotec modelo Supra, umedecidos com sílica coloidal em suspensão (OPS).

- $\quad$ Enxágüe com água destilada e álcool etílico.

- $\quad$ Secagem com jato de ar comprimido.

- $\quad$ Ataque químico com uma solução adequada para revelar a microestrutura. A solução usada para o Cobre Eletrolitico foi o reagente Klemm's e para o Cobre Cromo foi uma solução de $\mathrm{CrO} 3+\mathrm{H} 2 \mathrm{SO} 4$ com gotejamento de $\mathrm{HCl}$. A imersão foi rápida, em torno de 5 segundos.

- $\quad$ Identificação dos corpos de prova.

As medidas de dureza foram obtidas por meio de um microdurômetro digital na escala Vickers (Microhardnesstester FM700, da Future Tech). A carga aplicada foi de 50 gf e o tempo de aplicação da mesma foi de 9s. Para cada corpo de prova foram feitas 4 medidas no centro do corpo de prova, sob espaçamento mínimo de 4 vezes a diagonal média da impressão.

A microscopia óptica foi feita no Departamento de Materiais (DEMAR) da Escola de Engenharia de Lorena (EEL/USP). O microscópio utilizado foi o Axiovert 200.

Os ensaios de tração a quente foram realizados na Divisão de Materiais (AMR). Foi utilizada uma máquina Universal de Ensaios Instron, modelo 3382. A taxa de deformação utilizada no ensaio foi de $0,135 \mathrm{~mm} / \mathrm{min}$, segundo o item 9.6 .2 da norma E 21-09 [5]. O forno utilizado para aquecimento dos corpos de prova foi o forno Instron, modelo SF-16 2230. A Figura 2 mostra o corpo de prova acoplado à máquina de ensaio de tração. 


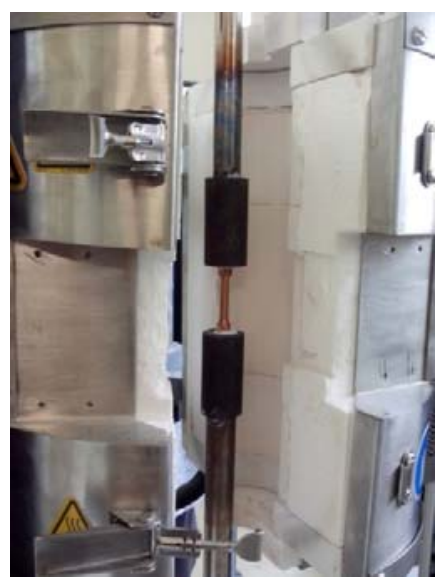

Figura 2. Preparação para o ensaio a quente do cobre eletrolítico

Os corpos de prova de cobre eletrolítico foram ensaiados a $27^{\circ} \mathrm{C}, 100^{\circ} \mathrm{C}, 200^{\circ} \mathrm{C}$, $250^{\circ} \mathrm{C}, 300^{\circ} \mathrm{C}, 350^{\circ} \mathrm{C}, 400^{\circ} \mathrm{C}, 450^{\circ} \mathrm{C}$ e $500^{\circ} \mathrm{C}$. Os corpos de prova de cobre cromo $\mathrm{C} 18200$ foram ensaiados a $27^{\circ} \mathrm{C}, 100^{\circ} \mathrm{C}, 300^{\circ} \mathrm{C}$ e $500^{\circ} \mathrm{C}$. Foram ensaiados 4 corpos de prova em cada temperatura, para o cobre eletrolítico e dois corpos de prova em cada temperatura para o cobre $\mathrm{C} 18200$. Totalizando 44 corpos de prova ensaiados e aproximadamente 2 meses de utilização da máquina de ensaio Instron da Divisão de Materiais do IAE (AMR/IAE). Os corpos de prova de tração foram elaborados de acordo com a norma ASTM E8/E8m [6], vide Figura 3.

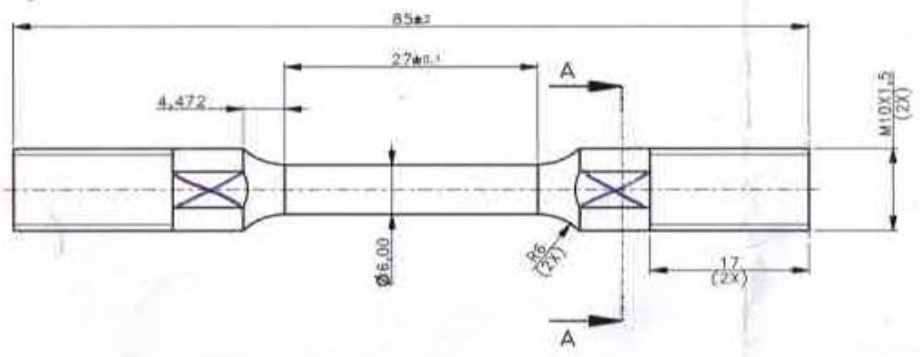

Figura 3. Desenho esquemático dos corpos de prova de tração

Como o ensaio foi realizado fora da temperatura ambiente, o processo de aquecimento e resfriamento do forno somente viabilizava o ensaio de um corpo de prova por dia. Após o forno atingir a temperatura estabelecida, o forno permaneceu 20 minutos no patamar de aquecimento. O resfriamento do corpo de prova até a temperatura ambiente foi realizado no forno.

Os ensaios de tração a quente possibilitaram investigar os limites elástico, as tensões máximas, e as deformações, em função das temperaturas de ensaio. $\mathrm{O}$ limite elástico foi calculado pelo método do limite elástico aparente de Jonhson [7], em substituição ao limite de escoamento a $0,5 \%$ da deformação do material [7]. Não foi usado extensômetro para medir a deformação do corpo de prova, pois o sistema de aquecimento do corpo de prova não permitia a utilização desse aparato. Sendo assim, a deformação foi cálculado utilizando o alongameto fornecido pelo software da máquina de ensaios de tração.

O procedimento do ensaio de tração a quente seguiu a sequência listada abaixo:

- $\quad$ Aplicação de leite de magnésia na borda do corpo de prova e na garra da haste, para evitar fusão do cobre.

- Posicionamento das hastes na maquina universal.

- $\quad$ Adaptação da haste na máquina com uma pré-carga de 30N. 
- Posicionamento do forno e aplicação de um isolante de óxido de sílica nas aberturas do forno.

- Funcionamento do controlador de temperatura, e aquecimento até a temperatura desejada.

- Após o forno atingir a temperatura de ensaio, os corpos de prova permaneceram 20 minutos nesse patamar, em seguida iniciou-se o ensaio de tração.

\section{RESULTADOS E DISCUSSÃO}

A Figura 4 apresenta as micrografias do cobre eletrolítico C11000 ensaiado nas temperaturas de 27 e $300^{\circ} \mathrm{C}$, respectivamente. Os grãos observados à temperatura ambiente apresentam maclação, que o principal mecanismo de deformação plástica dos grãos de cobre puro. O fenômeno de recristalização foi observado na Figura 4b, devido à diferença nos tamanhos dos grãos e no seu formato, quando comparado com a Figura 4a. O fenômeno de recristalização para esta amostra começou em temperaturas mais baixas que as encontradas na literatura (T 0,4Tf) [8].

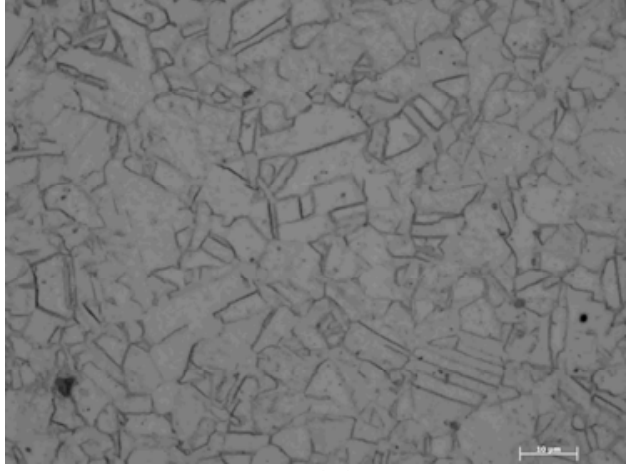

(a)

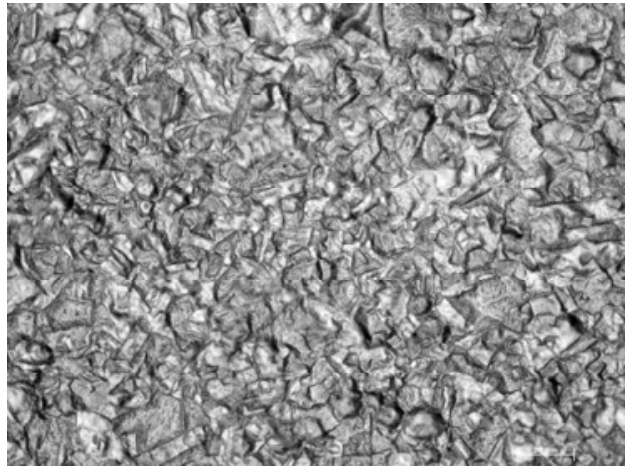

(b)

Figuras 4. Micrografia do cobre eletrolítico C 11000 ensaiadas em tração: a) $27^{\circ} \mathrm{C}$; b) $300^{\circ} \mathrm{C}$.

A Figura 5 apresenta as micrografias das amostras de Cobre Cromo C18200 ensaiadas a 27 e $300^{\circ} \mathrm{C}$. Não foram observadas diferenças microestruturais significativas entre as micrografias da Figura 5(a) e (b), diferentemente das análises do cobre puro. Neste caso, a presença de precipitados impede a movimentação dos contornos de baixo ângulo, diminuindo o efeito da temperatura sobre a recristalização.

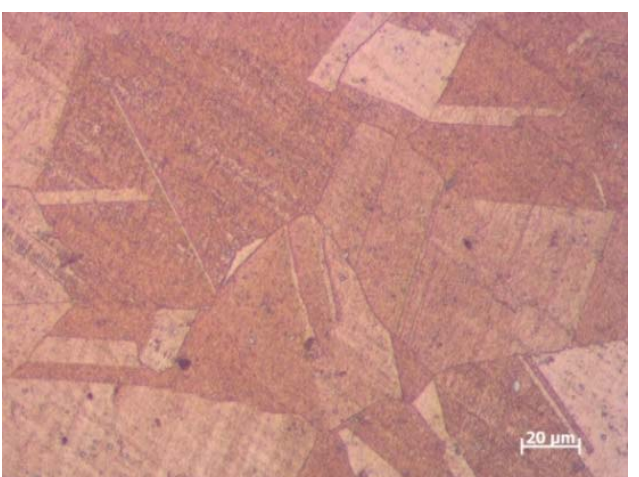

(a)

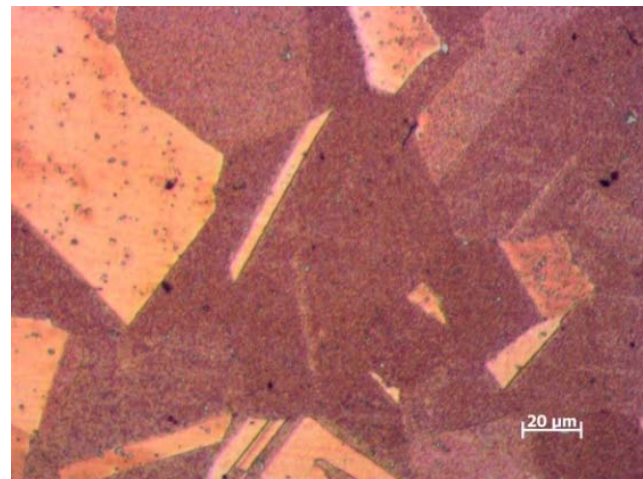

(b)

Figura 5. Micrografia do cobre cromo C18200 ensaiadas em tração: a) $27^{\circ} \mathrm{C}$; b) $300^{\circ} \mathrm{C}$. 
A Figura 6 apresenta os resultados obtidos dos ensaios de tração a quente para o cobre eletrolítico C11000. Observa-se na Figura 6 que à medida que a temperatura aumenta, há uma diminuição no limite de resistência do material. Observa-se também para temperaturas acima de $250^{\circ} \mathrm{C}$, que a forma da curva tração-deformação muda, não apresentando mais o ponto de inflexão. A temperatura de $350^{\circ} \mathrm{C}$ se mostra como um ponto de fragilidade, com baixa ductilidade, devido ao fim do processo de recristalização. A partir da temperatura de $400^{\circ} \mathrm{C}$, o cobre eletrolítico C11000 apresenta o fenômeno de amolecimento, o que está diretamente ligado ao crescimento de grão do material.

A Figura 7 apresentam os resultados obtidos dos ensaios de tração a quente para o cobre cromo C18200. Observa-se na Figura 7 que à medida que a temperatura aumenta, há uma diminuição no limite de resistência do material. O comportamento mecânico das amostras de cobre cromo se explica pelos seguintes fatos: O material ensaiado à temperatura ambiente apresenta-se muito encruado, devido ao processo de fabricação. Quanto o ensaio é realizado a $100{ }^{\circ} \mathrm{C}$ existe a relaxação das tensões e a ductilidade aumenta. Aumentando a temperatura, nota-se uma fragilidade devido à precipitação do cromo. O que aumenta com o aumento da temperatura.

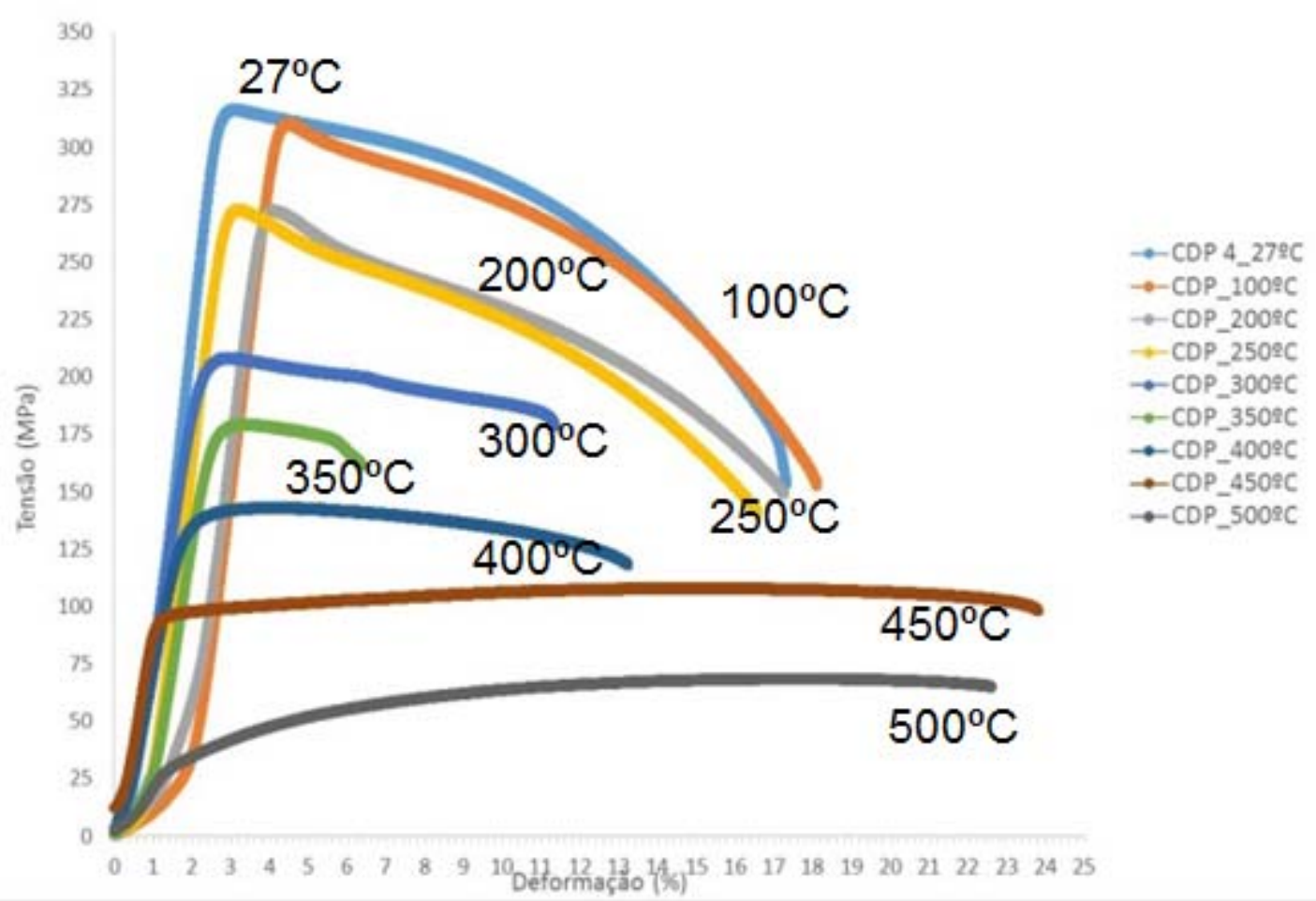

Figura 6. Comportamento mecânico do cobre eletrolítico C11000 sob diferentes temperaturas. 


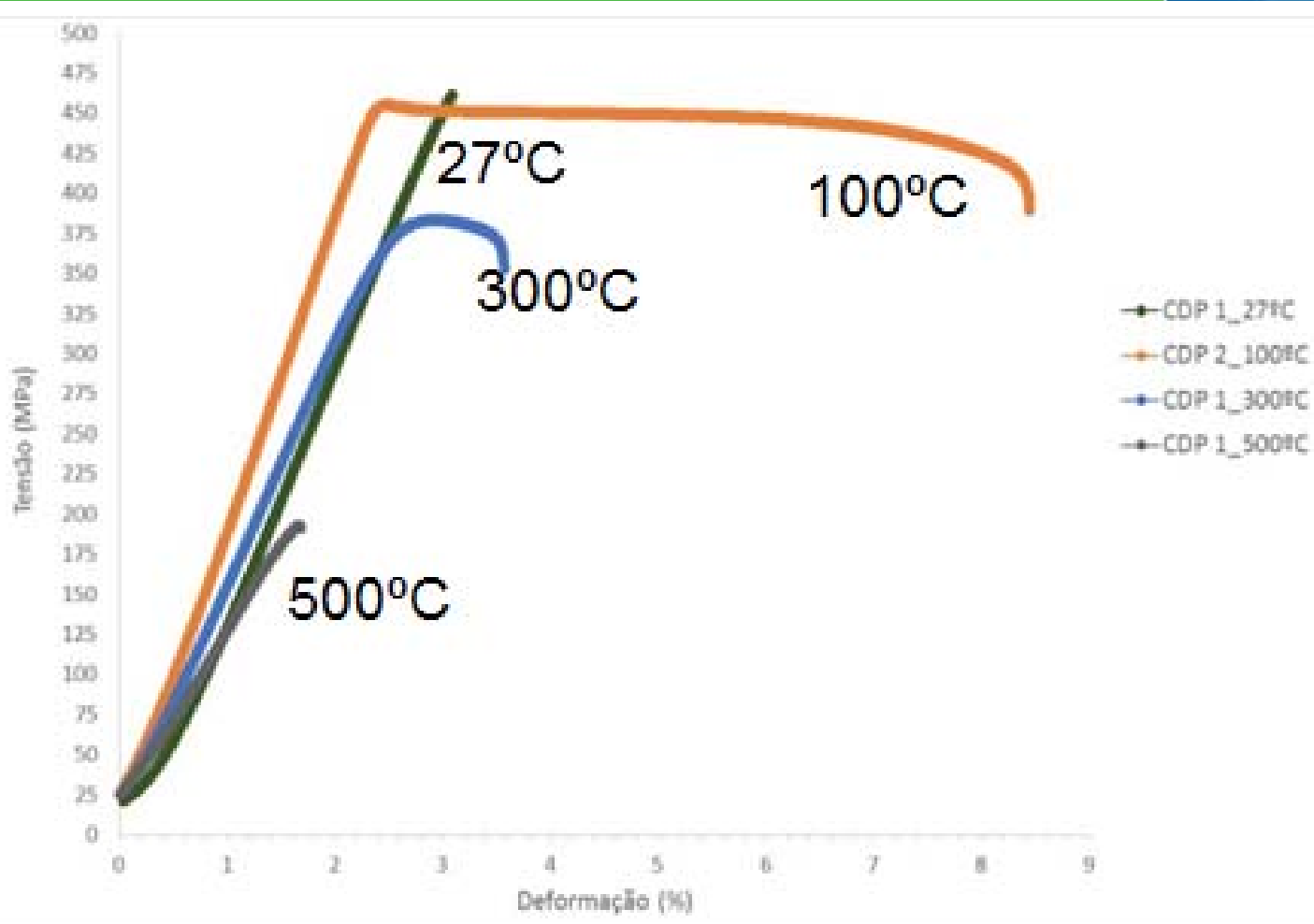

Figura 7. Comportamento mecânico do cobre cromo C18200 sob diferentes temperaturas.

As Tabelas 3 e 4 apresentam um resumo das propriedades mecânicas obtidas nos ensaios de tração a quente do cobre eletrolítico C11000 e do cobre cromo C18200, respectivamente. Pela análise dos dados das Tabelas 3 e 4, nota-se que a tensão de escoamento está próxima da tensão máxima. Isto é devido à estricção do material acontecer logo nos primeiros estágios da deformação plástica.

Tabela 3. Propriedades mecânicas em tração do cobre eletrolítico C11000.

\begin{tabular}{cccc}
\hline $\begin{array}{c}\text { Temperatura } \\
{ }^{\circ} \mathbf{C}\end{array}$ & $\begin{array}{c}\text { Tensão de } \\
\text { Escoamento } \\
(\mathbf{M P a})\end{array}$ & $\begin{array}{c}\text { Tensão Máxima } \\
\mathbf{( M P a )}\end{array}$ & $\begin{array}{c}\text { Deformação } \\
\mathbf{( \% )}\end{array}$ \\
\hline 27 & 303 & 317 & 17 \\
\hline 100 & 294 & 306 & 18 \\
\hline 200 & 262 & 283 & 17 \\
\hline 250 & 260 & 260 & 20 \\
\hline 300 & 190 & 217 & 13 \\
\hline 350 & 168 & 180 & 6 \\
\hline 400 & 120 & 143 & 13 \\
\hline 450 & 90 & 106 & 24 \\
\hline 500 & 23 & 69 & 23 \\
\hline
\end{tabular}

Tabela 4. Propriedades mecânicas em tração do cobre cromo C18200.

\begin{tabular}{cccc}
\hline $\begin{array}{c}\text { Temperatura } \\
{ }^{\circ} \mathbf{C}\end{array}$ & $\begin{array}{c}\text { Tensão de } \\
\text { Escoamento } \\
(\mathbf{M P a})\end{array}$ & $\begin{array}{c}\text { Tensão } \\
\text { Máxima (MPa) }\end{array}$ & $\begin{array}{c}\text { Deformação } \\
\mathbf{( \% )}\end{array}$ \\
\hline 27 & 451 & 461 & 3.1 \\
\hline 100 & 453 & 465 & 9.5 \\
\hline 300 & 356 & 376 & 3.6 \\
\hline 500 & 183 & 184 & 1.8 \\
\hline
\end{tabular}


As Figuras 8 a 10 apresentam uma comparação entre os resultados das amostras de cobre eletrolítico C11000 e da liga de cobre cromo C18200. Observou-se nas Figuras 8 e 9, que à medida que a temperatura de ensaio aumenta, a tensão máxima e a tensão de escoamento para ambos os materiais decrescem linearmente com a temperatura. Verifica-se na Figura 10 que, para as mesmas temperaturas de ensaio, o cobre eletrolítico C11000 apresenta uma maior ductilidade em relação ao cobre cromo C18200. A ação dos precipitados na liga cobre cromo diminui a mobilidade das discordâncias, portanto diminui a deformação plástica.

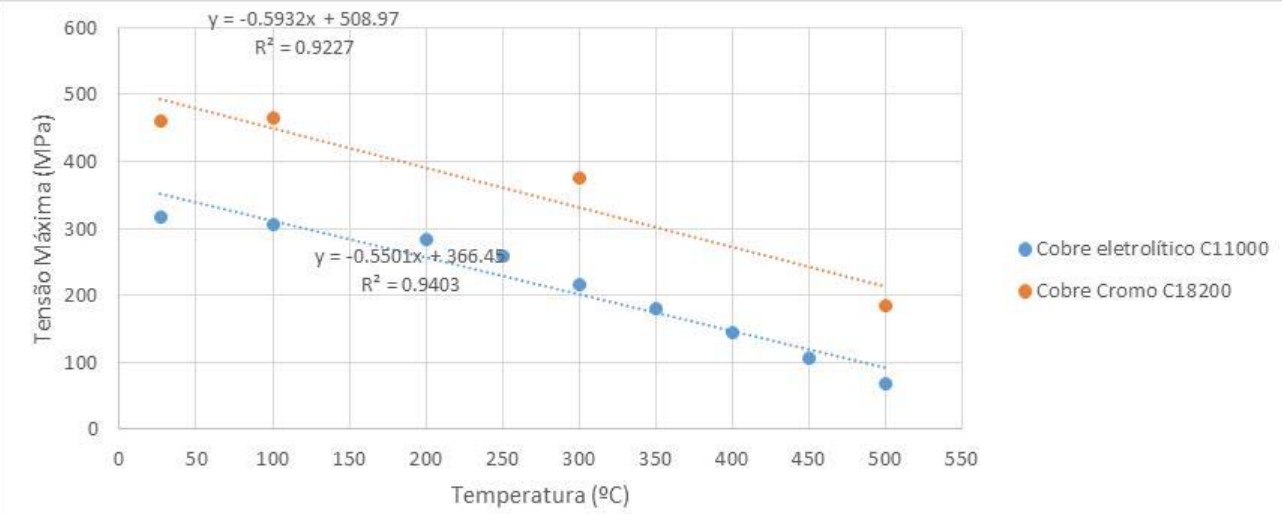

Figura 8. Comparação entre a tensão máxima do cobre eletrolítico C11000 e do cobre cromo C18200 em diferentes temperaturas.

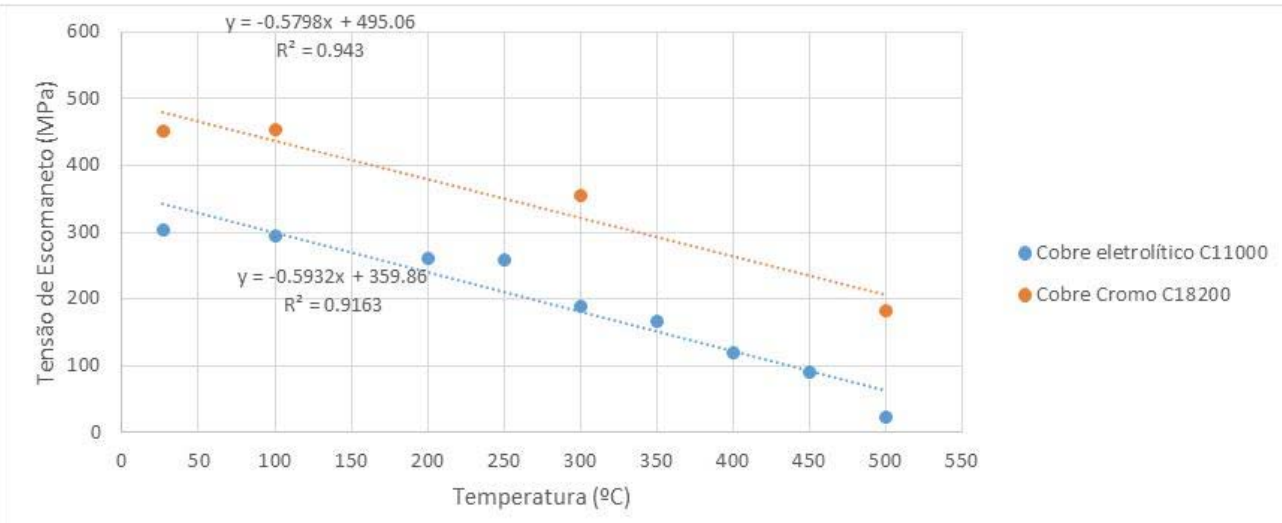

Figura 9. Comparação entre a tensão de escoamento do cobre eletrolítico C11000 e do cobre cromo C18200 em diferentes temperaturas.

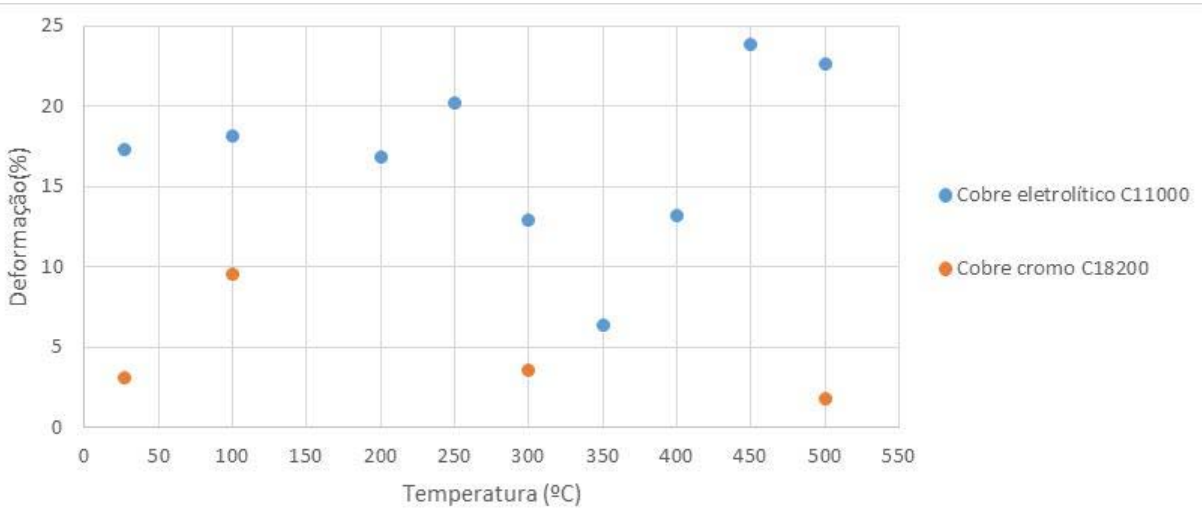

Figura 10. Comparação entre a deformação do cobre eletrolítico C11000 e do cobre cromo C18200 em diferentes temperaturas. 


\section{CONCLUSÃO}

Com este estudo foi possível obter as seguintes conclusões:

- A dureza do Cobre eletrolítico C11000 é $33 \%$ inferior à dureza do cobre cromo C18200 a temperatura ambiente.

- A resistência mecânica do cobre eletrolítico C11000 e do cobre cromo C18200 diminuem com o aumento da temperatura.

- A partir de $400^{\circ} \mathrm{C}$ o cobre eletrolítico C11000 apresenta amolecimento do material, devido ao crescimento de grão do material.

- Apesar do cobre cromo C18200 apresenta elevada resistência mecânica quando comparado ao cobre eletrolítico C11000, o cobre cromo apresenta baixa ductilidade (exceto a temperatura de $100^{\circ} \mathrm{C}$ ), resultando em um material frágil.

\section{Agradecimentos}

O L.B.S. agradece às seguintes instituições: Ao CNPQ pela bolsa PIBIC/IAE; ao Instituto de Aeronáutica e Espaço (IAE) pela bolsa institucional e por todo apoio à presente pesquisa e ao Instituto de Estudos Avançados (IEAv) pela utilização dos equipamentos.

\section{REFERÊNCIAS}

1 Almeida, J. da E. Motor Foguete a Propelente Líquido L75. Seminário de Projetos de Pesquisa e Desenvolvimento, São José dos Campos, 2012.

2 Gahun, G. G., 1989, "Construction and design of Liquid Rocket Engines", (in Russian), Moscow, Mashinostroenie Press, 424p.

3 R. P. Carreker, Jr. And W. R. Hibbard, Jr. Tensile deformation of High-Purity Copper as a function of temperature, strain rate e grain size. ACTA Metallurgica, Vol. 1, Nov. 1953, p. 654-663.

4 Ghica G.B. and Buzatu M. Tensile strength of $\mathrm{Cu}-\mathrm{Cr}$ alloy at elevated temperature. P.B. Sci. Bull., Series B, Vol. 70, No. 1, 2008, p. 55-60.

5 ASTM - American Society for Testing And Materials. E21-09. Standard Test Methods for Elevated Temperature Tension Tests of Metallic Materials. 2014.

6 ASTM - AMERICAN SOCIETY FOR TESTING AND MATERIALS. E8/E8M. Standard Test Methods for Tension Testing of Metallic Materials. 2013.

7 Souza, S. A. Ensaios Mecânicos de Materiais Metálicos. Fundamentos teóricos e práticos. $2^{\mathrm{a}}$ ed. São Paulo. Edgard Blucher, 1982.

8 A. F. Padilha, F. Siliciano Junior. Encruamento, recristalização, crescimento de grão e textura. ABM, $3^{\text {a }}$ Ed., 2005, p. 31.

\section{BIBLIOGRAFIA}

1 M. Scapin, L. Peroni and C. Fichera. Investigation of dynamic behaviour of copper at high temperature. Materials at High Temperatures, Vol. 31, No. 2, 2014, p. 131-140.

2 W. Gao, A. Belyakov, H. Miura, T. Sakai. Dynamic recrystallization of copper polycrystals with different purities. Materials Science and Engineering, A265, 1999, p. 233-239.

3 U. R. Andrade, M. A. Meyers, and A. H. Chokshi. Constitutive description of work- and shock-hardened Copper. Scripta Metallurgica et Materialia, Vol. 30, No. 7, 1994, p. 993938.

4 ASM Speciality Handbook. Copper and copper alloys. 2001. III series, p. 477. 